\title{
Legal responses to neuroscience
}

\author{
Johannes Fuss, MD
}

Recent decades have seen an increased interest in the neuroscientific understanding of aggressive, criminal and antisocial behaviours. ${ }^{1-4}$ Likewise, neuroscientific evidence has been increasingly introduced in criminal trials to explain criminal and mentally disordered behaviour. Four very recent studies that were performed in Canada, England and Wales, the Netherlands and the United States demonstrate that introducing neurobiological explanations of criminal behaviour into courtrooms seems to be on the rise in different legal systems. ${ }^{5-8}$ It is therefore important to address how such evidence shapes criminal cases and legal decisions.

\section{Why use neuroscience findings?}

So far, in most documented cases, abnormal brain activity or morphology has been introduced by the defence as a mitigating factor in the sentencing phase of criminal trials. This happens typically in high-stakes cases where defendants face a severe sentence, such as in death penalty cases in the United States. ${ }^{9,10}$ Evidence of abnormal brain activity is introduced as an indicator for reduced culpability of the defendant due to a mental disorder and thus follows a biological deterministic argument (in extreme cases, such evidence could be roughly summarized as, "his/her abnormal brain made him/her do it"). Important insights into how neuroscience affects court decisions in the United States were provided in a recent study by Denno ${ }^{9}$ analyzing all criminal cases ( 800 in total) in which neuroscientific evidence played a role over the course of 2 decades (1992-2012). Denno concluded from the data that neuroscience evidence is mainly used for mitigation "accompanied by a complex range of defense strategies." Surprisingly, she also found that many courts not only expect attorneys to stress neuroscience evidence, but also penalize attorneys who neglect this obligation. ${ }^{9}$

In most legal systems, legal responsibility is determined on a behavioural level, with psychopathology being the crucial argument for reduced culpability. Neuroscience evidence can help to buttress these psychopathological arguments. Interestingly, most of the cases with neuroscience evidence used clinically established techniques, such as structural imaging, positron emission tomography or electroencephalography
(EEG), to demonstrate brain damage; ${ }^{7}$ although this diagnosis seems to appear only in Canada, fetal alcohol spectrum disorder has also been used. ${ }^{8}$ Nevertheless, in a small percentage of cases, more recent neuroscience techniques, such as fMRI or neurogenetics were introduced as well. ${ }^{5,7}$ It can be expected that the use of $\mathrm{fMRI}$ and neurogenetics will increase in criminal trials in the future, given the excitement surrounding this research and its possible legal implications. ${ }^{11}$ To date, however, neuroscience findings typically report about group differences, and usually group differences from large samples cannot be applied to individual cases in criminal trials. ${ }^{12,13}$

\section{Attributing aggressive and criminal behaviours to genetics}

A large number of studies on the genetic basis of aggressive and criminal behaviours have been conducted in the past few years. They found that approximately $50 \%$ of the variance in aggressive and antisocial behaviours is attributable to genetics. ${ }^{14}$ However, no specific polymorphism could be linked to aggression in a recent meta-analysis, ${ }^{15}$ which indicates that a combination of a large number of variants (with a small effect size) is necessary to increase the risk for aggression. Probably the mostly studied gene in relation to antisocial and aggressive behaviours is the gene coding for the monoamine oxidase A (MAOA) enzyme. A point mutation in this gene leads to a complete deficiency of enzymatic activity that results in the so-called Brunner syndrome, a remarkable behavioural phenotype associated with dysregulated aggression and impulsivity. ${ }^{1}$ However, not only complete deficiency of the MAOA enzyme affects behaviour. The 2002 study by Caspi and colleagues ${ }^{2}$ found a gene $\times$ environment interaction, where carriers of an MAOA low-activity genotype who were maltreated during childhood had a significantly higher risk for adult antisocial behaviours. Male carriers of this genotype also have pronounced brain volume reductions in limbic structures and show altered brain functions. ${ }^{16}$ Moreover, a recent study reported a link between extremely violent behaviours (i.e., at least 10 committed homicides, attempted homicides or batteries) and an MAOA low-activity genotype in adults. ${ }^{4}$

Correspondence to: J. Fuss, Institute for Sex Research and Forensic Psychiatry, Martinistr. 52, Center for Psychosocial Medicine, University Medical Center Hamburg-Eppendorf, 20246 Hamburg, Germany; jo.fuss@uke.de

DOI: $10.1503 /$ jpn. 160147 


\section{Studying legal interpretations of neuroscience findings in the courtroom}

It has been argued that introduction of such neuroscience findings into courtroom battles is a double-edged sword. ${ }^{17,18}$ Either it mitigates a defendant's sentence because he/she is not held responsible for his/her biological makeup and thus legal responsibility and culpability might be reduced, or such evidence aggravates the sentence because the biological makeup will make the defendant commit further offenses in the future.

Recently (2012), Aspinwall and colleagues ${ }^{18}$ conducted a study to investigate which blade of this double-edged sword is sharper. They presented US state trial judges with a hypothetical criminal case that was largely based on the case of Mobley v. The State, ${ }^{19,20}$ which was one of the most famous US criminal cases of the last decades because it was the first in which MAOA could have played a role. ${ }^{21}$ The hypothetical case described a psychopath convicted of aggravated battery because he callously hit a store manager with a gun during a robbery attempt. Later, the psychopath bragged about his offense to fellow detainees. After reading the vignette, participating judges were randomly assigned to 1 cell of a $2 \times 2$ design ("presenting party": defence v. prosecution and "biomechanism": present v. absent). All judges $(n=181)$ received a psychiatric testimony about the defendant's psychopathy, and only half received an additional neurobiological explanation of psychopathy. The neurobiological explanation cited evidence about the low-activity MAOA genotype and brain function and reported that the psychopath was tested for this genotype. Testimonies were presented either by the prosecution or by the defence. While the defence argued that the testimonies should mitigate the sentence, the prosecution argued for aggravation. Subsequently, judges had to provide answers and a sentence for the psychopath.

Aspinwall and colleagues ${ }^{18}$ found that while the evidence concerning psychopathy was considered aggravating, the additional neuroscience evidence reduced the sentence from 14 years to less than 13 years. Surprisingly, the judges did not rate the defendant as having less legal responsibility.

This study was the first to experimentally investigate the influence of neuroscience on the judicial system, and it was in line with other real-life reports that neuroscience evidence is used to mitigate the sentence of defendants in the United States ${ }^{9,22}$ and in other legal systems. ${ }^{23,24}$

Some colleagues and I were interested in whether the mitigating effect of neuroscience evidence is a general tendency in the Western world even though there are substantial differences among Western legal systems. We thus repeated the study by Aspinwall and colleagues ${ }^{18}$ in the German legal system and recruited 372 German judges to respond to a translation of the same vignette. ${ }^{21}$ In the German legal system, profound differences in responses occurred. First, the evidence concerning psychopathy was seen as mitigating overall. This was not surprising because in the German legal system psychiatric experts are usually appointed to assess whether a convict has diminished or no legal responsibility for an offense because of a mental disorder. Moreover, a neuroscience explana- tion of psychopathy reduced judges' estimation of legal responsibility, yet the prison sentence was not affected in contrast to the US study. Most strikingly, we found that presentation of neuroscience evidence by the prosecution significantly increased the percentage of judges who ordered an involuntary commitment in a forensic psychiatric hospital $(23 \%$ v. $6 \%$ ) instead of a prison sentence. Such a commitment may increase the detention time dramatically and possibly for the rest of the convict's life. ${ }^{25}$ We argued that introduction of neuroscience evidence emphasizes that a psychiatric disorder is a brain disorder and, thus, the need for (involuntary) treatment seems to be considered greater. ${ }^{21}$ Such a neurobiological basis may reduce the legal responsibility, but nevertheless increase the likelihood for indeterminate involuntary commitment, especially for those who have disorders with limited treatment options or poor prognosis (e.g., psychopathy or paraphilic disorders). The study by Aspinwall and colleagues ${ }^{18}$ and our study ${ }^{21}$ demonstrate how neuroscience evidence receives different responses in 2 legal systems. Although the evidence was formally mitigating in both systems, it led to decreased detention time in the United States, whereas it possibly led to increased detention time in Germany.

The future will bring us a better understanding of the biological underpinnings of criminal and antisocial behaviours. Biological markers for violence and recidivism may help to improve the prediction of future offenses. A recent study found, for example, that low anterior cingulate activity during performance of an inhibitory task was associated with much higher rates of re-arrest among adult offenders within a time span of 4 years. ${ }^{3}$ If such findings can be replicated, they might one day lead to neuroscience becoming a part of standardized risk assessments. This might ultimately improve recidivism rates. Today, however, neuroscience is not at a stage where it could be considered predictive of future behaviours. No single polymorphism can be useful to foresee complex behaviours, such as aggression, as multiple genes with a small effect size seem to impact nondeterministically on brain function and thereby increase the risk for a certain behaviour only by a small degree. ${ }^{31}$ Thus, it appears premature to put much weight on genetic or imaging explanations for aggressive behaviour in criminal trials.

Neuroscientific understanding may open new avenues for the biological treatment of criminal and antisocial behaviours. For example, novel genome editing tools, such as clustered regularly interspaced short palindromic repeats (CRISPR)-Cas, might one day become available for sitespecific genomic modification of defective MAOA genes. ${ }^{1,26}$ Moreover, deep brain stimulation has been proposed as a means to selectively inhibit aggression ${ }^{27}$ or sexual drive. ${ }^{28}$ Such treatment options will bring up ethical issues (e.g., regarding informed consent) for treatment and punishment of offenders. ${ }^{28,29}$ They may also lead to psychopathologization of criminal behaviour that is currently not associated with mental disorders. Thus, it appears very important to study how such treatments may affect sentencing in the future.

The study by Aspinwall and colleagues ${ }^{18}$ and our study ${ }^{21}$ investigated the influence of a specific construct (psychopathy) and specific neurogenetic evidence on sentencing. We 
do not know if these findings can be translated to other disorders (e.g., psychosis, other personality or paraphilic disorders) or to other biological evidence (e.g., fMRI or quantitative EEG). Moreover, a recent study found that biological explanations of mental disorders evoked less empathy than psychosocial explanations in US clinicians. ${ }^{30}$ Thus, psychiatric expert testimonies may also be affected by neuroscience evidence.

\section{Conclusion}

There are still many important research questions left unanswered. Studying the intersection between neuroscience and the law is crucial not only to understand how concepts of legal responsibility and punishment are affected in different legal systems, but also to reflect the use of neuroscientific techniques for diagnosis, risk assessment and treatment. Researchers, clinicians and judges should be cautious not to be overinclusive on the behavioural implications of a biological finding that may well be incidental to rather than causal of a certain behaviour.

Affiliations: From the Institute for Sex Research and Forensic Psychiatry, Center for Psychosocial Medicine, University Medical Center Hamburg-Eppendorf, Germany.

Competing interests: None declared.

\section{References}

1. Brunner HG, Nelen M, Breakefield XO, et al. Abnormal behavior associated with a point mutation in the structural gene for monoamine oxidase A. Science 1993;262:578-80.

2. Caspi A, McClay J, Moffitt TE, et al. Role of genotype in the cycle of violence in maltreated children. Science 2002;297:851-4.

3. Aharoni E, Vincent GM, Harenski CL, et al. Neuroprediction of future rearrest. Proc Natl Acad Sci U S A 2013;110(15):6223-8.

4. Tiihonen J, Rautiainen MR, Ollila HM, et al. Genetic background of extreme violent behavior. Mol Psychiatry 2015;20:786-92.

5. Catley P, Claydon L. The use of neuroscientific evidence in the courtroom by those accused of criminal offenses in England and Wales. J Law Biosci 2015;2:510-49.

6. De Kogel $\mathrm{CH}$, Westgeest EJMC. Neuroscientific and behavioral genetic information in criminal cases in the Netherlands. J Law Biosci 2015;2:580-605.

7. Farahany NA. Neuroscience and behavioral genetics in US criminal law: an empirical analysis. J Law Biosci 2015;2:485-509.

8. Chandler JA. The use of neuroscientific evidence in Canadian criminal proceedings. J Law Biosci 2015;2:550-79.

9. Denno DW. The myth of the double-edged sword: an empirical study of neuroscience evidence in criminal cases. Boston College Law Review 2015;56:493-551.

10. Meixner JB. The use of neuroscience evidence in criminal proceedings. J Law Biosci 2016.

11. Morse SJ. Actions speak louder than images: the use of neuroscientific evidence in criminal cases. J Law Biosci 2016.
12. Buckholtz J, Meyer-Lindenberg A. MAOA and the bioprediction of antisocial behavior: science fact and science fiction. In: Singh I, Sinnott-Armstrong WP, Savulescu J, editors. Bioprediction, biomarkers, and bad behavior: scientific, legal, and ethical challenges. New York: Oxford University Press; 2013. p. 131-52.

13. Faigman DL, Monahan J, Slobogin C. Group to individual (G2i) inference in scientific expert testimony. University of Chicago Law Review 2014;81:417-80.

14. Glenn AL, Raine A. Neurocriminology: implications for the punishment, prediction and prevention of criminal behaviour. Nat Rev Neurosci 2014;15:54-63.

15. Vassos E, Collier DA, Fazel S. Systematic meta-analyses and field synopsis of genetic association studies of violence and aggression. Mol Psychiatry 2014;19:471-7.

16. Meyer-Lindenberg A, Buckholtz JW, Kolachana B, et al. Neural mechanisms of genetic risk for impulsivity and violence in humans. Proc Natl Acad Sci U S A 2006;103:6269-74.

17. Gurley JR, Marcus DK. The effects of neuroimaging and brain injury on insanity defenses. Behav Sci Law 2008;26:85-97.

18. Aspinwall LG, Brown TR, Tabery J. The double-edged sword: Does biomechanism increase or decrease judges' sentencing of psychopaths? Science 2012;337:846-9.

19. Mobley v. The State. Supreme Court of Georgia; 1995.

20. Mobley v. Head. United States District Court for the Northern District of Georgia; 2001.

21. Fuss J, Dressing H, Briken P. Neurogenetic evidence in the courtroom: a randomised controlled trial with German judges. J Med Genet 2015;52:730-7.

22. State v. Davis Bradley Waldroup. Tenn. Crim. App., at Knoxville; 2011.

23. Italian court reduces murder sentence based on neuroimaging data. Nature News Blog; 2011. Available: http://blogs.nature.com /news/2011/09/italian_court_reduces_murder_s.html (accessed 2016 Sept. 22).

24. Nature News. Lighter sentence for murderer with 'bad genes'. Nature; 2009. Available: www.nature.com/news/2009/091030 /full/news.2009.1050.html (accessed 2016 Sept. 22).

25. Kröber HL, Lau S. Bad or mad? Personality disorders and legal responsibility — the German situation. Behav Sci Law 2000;18:679-90.

26. Heidenreich M, Zhang F. Applications of CRISPR-Cas systems in neuroscience. Nat Rev Neurosci 2016;17:36-44.

27. Franzini A, Broggi G, Cordella R, et al. Deep-brain stimulation for aggressive and disruptive behavior. World Neurosurg 2013;80:S29 e11-4.

28. Fuss J, Auer MK, Biedermann SV, et al. Deep brain stimulation to reduce sexual drive. J Psychiatry Neurosci 2015;40:429-31.

29. Meynen G. Neurolaw: recognizing opportunities and challenges for psychiatry. J Psychiatry Neurosci 2016;41:3-5.

30. Lebowitz MS, Ahn WK. Effects of biological explanations for mental disorders on clinicians' empathy. Proc Natl Acad Sci U S A 2014;111:17786-90.

31. Dorfman HM, Meyer-Lindenberg A, Buckholtz JW. Neurobiological mechanisms for impulsive-aggression: the role of MAOA. Curr Top Behav Neurosci 2014; 17:297-313. 